\title{
O ESTÍMULO DO INOVAR-AUTO AO DESENVOLVIMENTO DE MATERIAIS ECOLÓGICOS E VEÍCULOS MAIS EFICIENTES: UMA REFLEXÃO
}

\author{
Erik Telles Pascoal ${ }^{1}$, Antônio Lopes Nogueira da Silva ${ }^{2}$ \\ ${ }^{1,2}$ UNESP-FEG \\ E-mails: erik.telles@feg.unesp.br, antoniolopes83@bol.com.br
}

\section{RESUMO}

Apelos ecológicos para o desenvolvimento de novos materiais para a produção de veículos mais eficientes têm estimulado a busca de soluções tecnológicas inovadoras pela indústria automotiva que, anualmente, investe parte de seu faturamento em atividades de P\&D.

De encontro a este cenário e, também como premissa de alavancar ainda mais os investimentos em P\&D e colocar o país na rota do desenvolvimento global e sustentável, o governo brasileiro lançou em 2012 o Programa de Incentivo à Inovação Tecnológica e Adensamento da Cadeia Produtiva de Veículos Automotores, denominado Inovar-Auto. O programa tem como principais objetivos o apoio ao desenvolvimento tecnológico, à inovação, segurança e eficiência energética.

O presente artigo tem como objetivo apresentar algumas tendências mundiais referentes à utilização de novos materiais e novas soluções tecnológicas que estão sendo desenvolvidas para a produção de veículos mais eficientes. Espera-se que estas informações contribuam na reflexão do setor automotivo nacional e, que os incentivos do Inovar-Auto possam fomentar o desenvolvimento das mesmas no âmbito do mercado brasileiro.

\section{INTRODUÇÃO}

Diversos setores da economia mundial vêm se deparando com um movimento que, cada vez mais, vem ganhando força, impactando expressivamente vários mercados, inclusive $o$ automotivo, que são os chamados apelos ambientais. Além dos benefícios ambientais, a geração de receita proveniente dos desenvolvimentos sustentáveis ganha mais espaço nas organizações, já que tanto as empresas quanto os poderes governamentais estão empenhados a investir em produtos ecológicos.

$\mathrm{Na}$ indústria automotiva, a busca de novos materiais para a produção de veículos mais eficientes é irreversível [1]. Tem-se observado, em determinados casos, o desenvolvimento de novas peças ou mesmo a sua substituição completa [1]. A aplicabilidade desses itens na produção de automóveis está sendo tratado como prioridade pelas as montadoras que buscam, cada vez mais, veículos mais leves, menos poluentes, mais econômicos e mais eficientes. Estas iniciativas têm estimulado a inovação em toda a cadeia produtiva e, como exemplo, podemos citar a utilização crescente dos chamados "pneus verdes" que possuem um menor coeficiente de atrito, menor desgaste e maior durabilidade, gerando significativos ganhos ambientais [2]. 
Dentro deste contexto de busca de soluções tecnológicas ecológicas e inovadoras, o governo brasileiro regulamentou recentemente uma nova política industrial para o setor automotivo, denominada de Inovar-Auto, que dentre os seus principais objetivos estão o desenvolvimento de $\mathrm{P} \& \mathrm{D}$, proteção ao meio ambiente e a melhoria da eficiência energética dos veículos.

Neste cenário uma importante questão vem à tona: o Inovar-Auto conseguirá fomentar o desenvolvimento local de novos materiais e novas soluções tecnológicas para a produção de veículos mais eficientes pela indústria automotiva brasileira? Este artigo se propõe a fazer uma reflexão sobre este tema.

\section{UM BREVE HISTÓRICO DE ALGUNS MATERIAIS UTILIZADOS NA INDÚSTRIA AUTOMOTIVA}

No decorrer do último século a indústria automotiva vem passando por grandes transformações, não sendo diferente no processo de escolha dos materiais empregados nos automóveis. Um breve histórico de alguns desses eventos é descrito a seguir:

- 1911: ocorre a padronização do primeiro aço pela SAE (Standard American Engineering), o SAE 1050, juntamente com aumento de ênfase dada à metalurgia dos materiais com a conscientização do tratamento térmico como ciência [1];

- 1915: início da utilização do alumínio na indústria automotiva [1];

- Década de 30: o alumínio ganha ainda mais força e substitui o ferro fundido na fabricação do pistão do motor [1];

- 1936: a Volkswagen começa a utilizar magnésio fundido na confecção do eixo de manivela, no sistema de transmissão do motor e em outras pequenas partes, proporcionando um automóvel $50 \mathrm{~kg}$ mais leve, representado cerca de 7\% do seu peso total [1];

- Década de 40: o nylon é introduzido como material automotivo pela Du Pont, sendo o primeiro material polimérico sintético utilizado em automóveis [3]. Na Alemanha o bronze começa a ser substituído por novas ligas de zinco e alumínio;

- Década de 50: Por ser leve, resistente e facilmente moldado em formas complexas, a presença de materiais poliméricos ganha mais expressão em veículos lançados na época. Em contra partida seu processo de fabricação era lento e sua pintura dispendiosa [1];

- Década de 60 a 70: mesmo com suas limitações os plásticos aumentam sua participação nos automóveis em $34 \mathrm{~kg}$, ocorrendo, principalmente, em componentes decorativos no interior dos veículos [1];

- Década de 70 a 80: a aplicação de materiais compósitos vem se desenvolvendo gradativamente. Porém seu uso ainda fica restrito a aplicações decorativas e semiestruturais [1].

Atualmente, o mercado dispõe de diversos materiais inovadores. A fibra de carbono, por exemplo, é um dos materiais que lidera essa lista, se tornando o material preferido na indústria 
aeroespacial por apresentar em sua combinação uma maior rigidez e melhor resistência mecânica e à fadiga. Sua desvantagem é o alto preço tornando sua aplicação limitada na produção de automóveis [1].

Também apresentando uma aplicação tímida devido ao seu alto custo, o alumínio vem despertando grande interesse na fabricação de veículos devido sua baixa densidade sendo encontrado nas carrocerias de veículos premium e na fabricação de motores [1].

Já os materiais cerâmicos são ao mesmo tempo os mais avançados e os menos difundidos também por conta de seu alto custo de fabricação. Porém, seu uso traz melhorias no desempenho do motor reduzindo a emissão de gases poluentes e na economia de combustível acenando de forma favorável aos interesses ambientais [1].

\section{NOVAS PROMESSAS, NOVOS PARADIGMAS}

A crescente busca por materiais mais resistentes, mais leves e ecologicamente corretos tem levado as empresas a buscarem soluções cada vez mais inovadoras como é o exemplo da Plastic Omnium.

Há algumas décadas, a indústria automotiva vem utilizando materiais compósitos, porém seu emprego ficava restrito na fabricação de certas peças de acabamento e semiestruturais como painéis de bordo e tetos. Mas este cenário está prestes a mudar com a proposta inovadora da Plastic Omnium em estender sua utilização às peças estruturais propriamente ditas, como estrutura entre as portas laterais onde se fixam os cintos de segurança e, ainda nos assoalhos traseiros [4]. Estas são consideradas uma das últimas regiões do veículo com potenciais ganhos de massa [4].

A grande promessa desta solução tecnológica é contribuir fortemente na produção de veículos mais leves com o objetivo de reduzir a emissão de poluentes. Entretanto, o grande paradigma é ganhar a batalha com os aços que, tradicionalmente, são os principais materiais estruturantes. Esta inovação tem ainda uma potencial vantagem a seu favor, que num futuro próximo sua ampla aplicação venha otimizar os processos de fabricação, eliminando, por exemplo, os banhos de cataforese para tratar as superfícies ou cabines de pintura [4].

\section{O INOVAR-AUTO E OS INCENTIVOS AS ATIVIDADE DE P\&D E MELHORIA DA EFICIÊNCIA ENERGÉTICA}

O governo brasileiro aprovou em outubro de 2012, por decreto uma nova política para a indústria automotiva nacional. O Programa de Incentivo à Inovação Tecnológica e Adensamento da Cadeia Produtiva de Veículos Automotores, denominado Inovar-Auto entrou em vigor em janeiro de 2013 com validade até dezembro de 2017, e faz parte da política industrial, tecnológica e de comércio exterior do Brasil chamada de Plano Brasil Maior [5], [6].

Esta nova política é específica para as montadoras que produzem no Brasil e também aquelas que não produzem, mas comercializem veículos no País, bem como aquelas que tenham projeto de investimento aprovado para instalação de fábrica no Brasil e abrangem os automóveis e comerciais leves, caminhões, chassis com motor e autopeças. E os seus 
principais objetivos são: apoiar o desenvolvimento tecnológico, a inovação, a segurança, a proteção ao meio ambiente, a eficiência energética e a qualidade dos veículos e autopeças [5], [6], [7], [8], [9].

Como benefício, o Inovar-Auto prevê a concessão de crédito presumido de IPI (Imposto sobre Produtos Industrializados) sobre as aquisições de insumos estratégicos e ferramentaria, gastos com pesquisa, desenvolvimento tecnológico, inovação tecnológica e recolhimentos ao FNDCT (Fundo Nacional de Ciência e Tecnologia) e dispêndios com engenharia e tecnologia industrial básica e capacitação de fornecedores [5], [6], [9].

Para a habilitação ao programa, as empresas deverão atender duas condições gerais: a) regularidade em relação aos tributos federais; e b) assumir o compromisso de atingir os níveis mínimos de eficiência energética para os veículos comercializados no país [5], [6].

Além disto, em relação às condições específicas, as montadoras de veículos leves deverão necessariamente realizar no país uma quantidade mínima de atividades fabris e de infraestrutura de engenharia em pelo menos $80 \%$ dos veículos fabricados e escolher no mínimo dois dos três requisitos a seguir: (1) investimentos em P\&D, (2) investimentos em engenharia, tecnologia industrial básica e capacitação de fornecedores, e (3) aderir ao Programa de Etiquetagem Veicular [5], [6], [10], [11]. As montadoras também poderão obter um desconto adicional de 1-2\% no IPI caso ultrapassem os níveis mínimos de eficiência energética [5], [6], [11]. Os requisitos de eficiência energética e P\&D, objeto deste artigo, estão descrito nos próximos subitens.

\subsection{Eficiência Energética}

O Inovar-Auto define como eficiência energética os níveis de autonomia expressos em quilômetros por litro de combustível $(\mathrm{Km} / \mathrm{l})$ ou níveis de consumo energético expressos em megajoules por quilômetro (MJ/Km).

Para obter os benefícios do programa, os veículos de passageiros que são comercializados no país deverão ter uma melhoria obrigatória mínima de 12,0\% em eficiência energética para 2017 (em relação aos níveis de 2012) [5], [6]. Esta meta foi baseada nos níveis Europeus para 2015 para os veículos de passageiros de $130 \mathrm{~g}$ de $\mathrm{CO}_{2} / \mathrm{Km}$, e adaptado para o Brasil devido às diferenças de ciclo de condução, características do veículo, combustível e especificações das estradas. As montadoras também poderão se qualificar para um desconto de $1 \%-2 \%$ adicionais no IPI, atendendo metas de eficiência mais agressivas conforme apresentado na Figura 1. 
Figura 1: Metas de Eficiência Energética.

\begin{tabular}{|c|c|c|c|c|}
\hline \multirow[b]{2}{*}{ Metas } & \multicolumn{2}{|c|}{ Autonomia Km/l } & \multirow{2}{*}{$\begin{array}{c}\text { Consumo } \\
\text { energético } \\
\mathbf{M J} / \mathbf{K m}\end{array}$} & \multirow{2}{*}{$\begin{array}{l}\text { Melhoria } \\
\text { eficiência } \\
\text { energética }\end{array}$} \\
\hline & Gasolina & Etanol & & \\
\hline Referência - 2012 & 14,00 & 9,71 & 2,07 & -- \\
\hline Meta para habilitação & 15,93 & 11,04 & 1,82 & $12,08 \%$ \\
\hline Meta para redução de 1\% no IPI - 2017 & 16,57 & 11,48 & 1,75 & $15,46 \%$ \\
\hline Meta para redução de $2 \%$ no IPI - 2017 & 17,26 & 11,96 & 1,68 & $18,84 \%$ \\
\hline
\end{tabular}

Fonte: Adaptado MDIC [5].

O requisito de eficiência energética é obrigatório e as penalidades pelo não cumprimento são altas o suficiente para incentivar as montadoras a cumprirem as metas. Conforme estipulado pelo governo, em caso de descumprimento das metas de eficiência energética, as montadoras pagarão multas de até $\mathrm{R} \$ 360,00$ por veículo [12]. Os resultados esperados pelo Inovar-Auto em termos de redução dos níveis de emissões de $\mathrm{CO}_{2}$ e demanda de gasolina estão representados nas Figuras 2 e 3.

Figura 2: Impacto nas Emissões de $\mathrm{CO}_{2}$ por Veículos Leves (mil t).

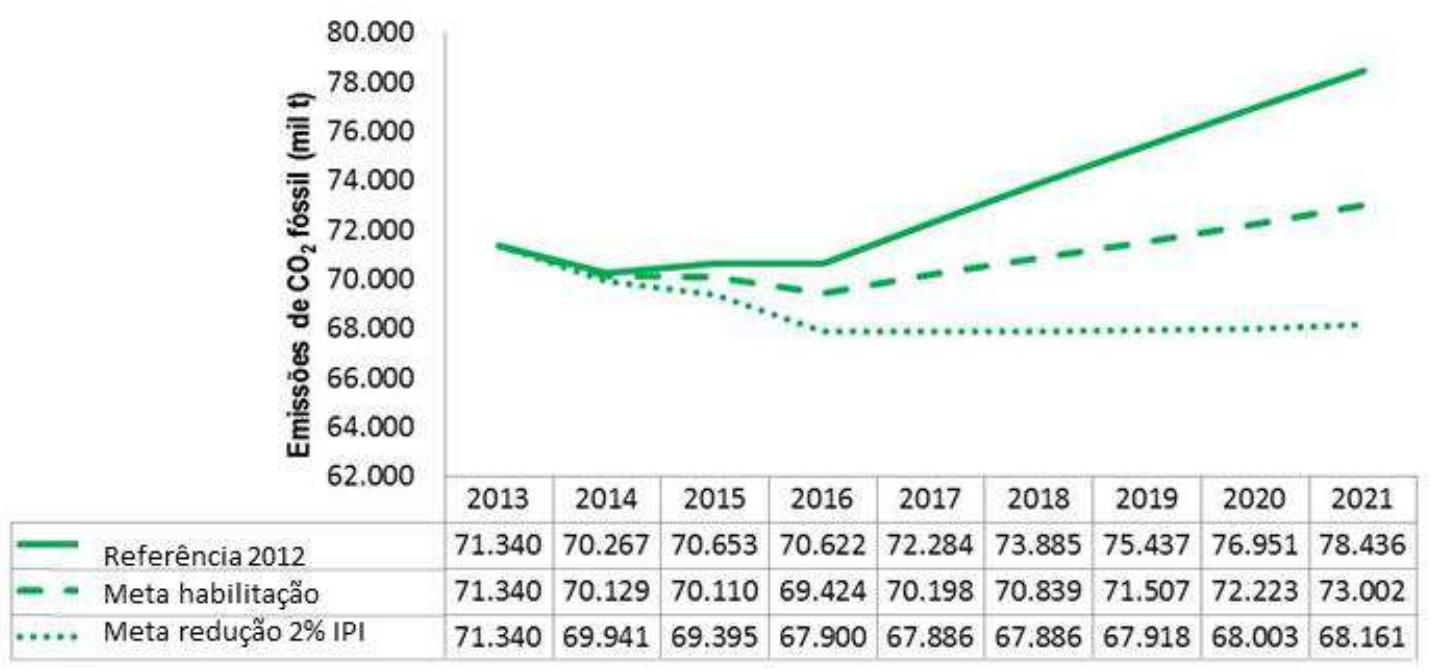

Fonte: IEMA [13].

Espera-se que acumuladamente que entre 2014 e 2021, as emissões evitadas de $\mathrm{CO}_{2}$, estarão entre 21,1 milhões $\mathrm{t}$ (meta habilitação) e 41,5 milhões $\mathrm{t}$ (meta redução $2 \%$ IPI) [13]. 
Figura 3: Impacto na Demanda por Gasolina.

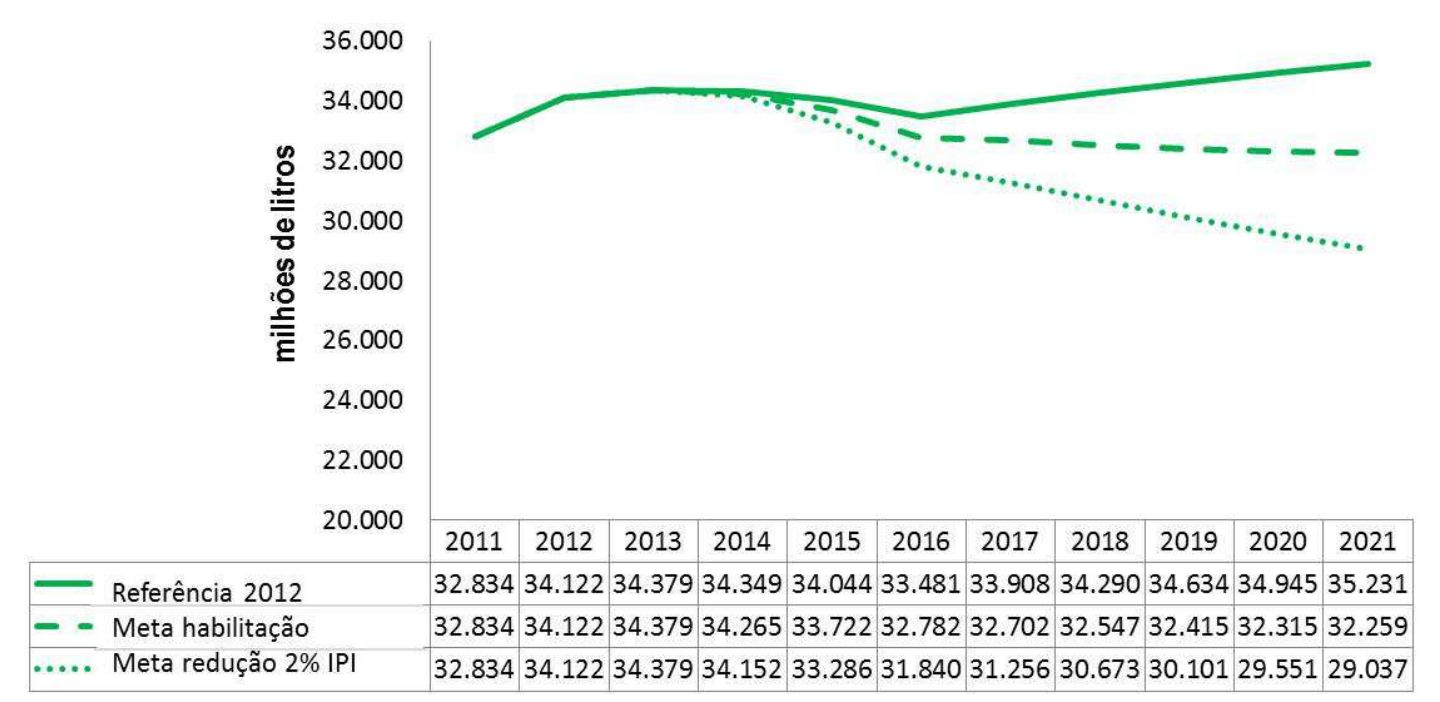

Fonte: Adaptado IEMA [13].

Espera-se que acumuladamente que entre 2014 e 2021, a economia de gasolina, estará entre 12 bilhões de litros (meta habilitação) e 28 bilhões de litros (meta redução $2 \%$ IPI) [13].

\subsection{Pesquisa e Desenvolvimento - P\&D}

As montadoras deverão realizar, no país, dispêndios em pesquisa e desenvolvimento em percentuais mínimos, descritos na Figura 4, incidentes sobre a receita bruta total de vendas de bens e serviços, excluídos os impostos e contribuições incidentes sobre a venda [5], [6].

Figura 4: Percentuais Mínimos dos Dispêndios em P\&D, Engenharia, Tecnologia Industrial Básica e Capacitação de Fornecedores.

\begin{tabular}{|c|c|}
\hline Ano & $\begin{array}{l}\text { Percentuais mínimos de investimentos } \\
\text { em pesquisa e desenvolvimento (P\&D) }\end{array}$ \\
\hline $\mathbf{2 0 1 3}$ & $0,15 \%$ \\
\hline $\mathbf{2 0 1 4}$ & $0,30 \%$ \\
\hline $\mathbf{2 0 1 5}$ & $0,50 \%$ \\
\hline $\mathbf{2 0 1 6}$ & $0,50 \%$ \\
\hline $\mathbf{2 0 1 7}$ & $0,50 \%$ \\
\hline
\end{tabular}

Fonte: Adaptado de MDIC [5], [6]. 
O Inovar-Auto considera como atividade de $P \& D$ a pesquisa básica dirigida, a pesquisa aplicada, o desenvolvimento experimental e o serviço de apoio técnico. Também poderá ser considerado o desenvolvimento de novos dispositivos de segurança veicular ativa e passiva, desde que sejam incorporados aos produtos até 30/07/2017 e constituam-se avanços funcionais e tecnológicos em relação aos previstos pelo Conselho Nacional de Trânsito (CONTRAN) [5], [6].

\section{DISCUSSÕES E CONCLUSÃO}

A preferência por medidas ecológicas e sustentáveis tende a aumentar e se tornar uma excelente estratégia de negócio dentro do mercado competitivo. A aplicação dessas medidas serão um diferencial no mercado automotivo, atendendo a um novo perfil de cliente, focado na preservação ambiental e no uso consciente da tecnologia.

É perceptível que a indústria automotiva está caminhando cada vez mais para a concepção de veículos ecologicamente corretos [1]. Porém, o que ainda restringe o rápido avanço de tais projetos são os elevados investimentos e o alto valor de mercado para o cliente final. Algumas ações governamentais, entretanto, já vêm oferecendo apoio a estas iniciativas, o que contribui para redução de seus custos de desenvolvimento.

No Brasil, o emprego de um novo material em larga escala leva em média de 5 a 10 anos para entrar no mercado. Este prazo se faz necessário para obtenção de recursos para que suas pesquisas sejam desenvolvidas, seja em laboratórios de grandes universidades ou em centro de pesquisas. Há uma necessidade de se passar por uma série de testes experimentais e avaliações de sua propriedade, capacitação e treinamento de pessoal, realização de teste de aprovação e aceitabilidade social, burocracia técnica, análise sobre o impacto ambietal, até chegar ao consumidor final.

Neste sentido, espera-se que os incentivos do Inovar-Auto, através dos requisitos de eficiência energética e $\mathrm{P} \& \mathrm{D}$, funcionem como um catalisador neste processo de desenvolvimento de novos materiais ecológicos e de veículos mais eficientes para a indústria automotiva brasileira nos próximos anos.

O mecanismo para impulsionar todo este processo desenvolvimento também já está desenhado pelo programa. Os elevados valores das multas a serem pagas pelas montadoras pelo não cumprimento das metas de eficiência energética promoverão uma aceleração nas pesquisas e desenvolvimentos de novas soluções tecnológicas inovadoras. Por outro lado, os esforços das montadoras serão recompensados caso elas ultrapassem os níveis mínimos de eficiência energética através de um desconto adicional de 1-2\% no IPI. Sem dúvida, aquelas montadoras que alcançarem estes benefícios fiscais adicionais estarão tendo uma grande vantagem estratégica num ambiente tão competitivo que é a indústria automotiva brasileira.

Em resumo, não seria irrealista apostar que o Inovar-Auto contribuirá para o desenvolvimento de novos materiais e novas soluções tecnológicas para a produção de veículos mais eficientes pela indústria automotiva brasileira. 


\section{REFERÊNCIAS}

[1] Araújo, M. R., Naveiro, R. M. Desenvolvimento de novos materiais e novos produtos na indústria automobilística (1999). Anais do Encontro Nacional de Engenharia de Produção - Enegep, 03 a 04 de nov. 1999, Rio de Janeiro, RJ.

[2] CNI - Confederação Nacional da Indústria. A Indústria Automobilística e Sustentabilidade (2012). Disponível em:

http://www.cni.org.br/portal/data/pages/FF80808137E2BEF70138013980B84DD1.htm. Acesso em: 22/01/2014.

[3] BRAGG G., Materials: Key to 100 Years of Automotive Progress. Automotive Engineering, december, pp-93-99, 1996.

[4] Depagneux , M.A. Plastic Omnium accélère avec les voitures écolos et allégées. Disponível em : http://www.latribune.fr/entreprisesfinance/industrie/automobile/20140210trib000814509/plastic-omnium-accelere-avec-lesvoitures-ecolos-et-allegees.html. Acesso em: 03/05/2014.

[5] MDIC - Ministério do Desenvolvimento, Indústria e Comércio, Lei No 12.715. (2012a). Disponível em http://www.planalto.gov.br/ccivil_03/_ato2011-2014/2012/lei/112715.htm. Acesso em 26/01/2014.

[6] MDIC - Ministério do Desenvolvimento, Indústria e Comércio, Decreto No 7.819. (2012b). Disponível em http://www.planalto.gov.br/ccivil_03/_ato20112014/2012/Decreto/D7819.htm. Acesso em 26/01/2014.

[7] IBUSUKI, U., BERNARDES, R. C., CONSONI, F., SAITO, O. M. (2012). New Brazilian Automobile Industrial Policy (Plano Brasil Maior): risks and opportunities for the sector. 20th International Colloquium of GERPISA, 30th-31st of May and 1st of June 2012, Krakow, Poland.

[8] IBUSUKI, U., KOBAYASHI, H., JIN, Y. (2013). Asian Automobile Manufacturers Strategies in Brazil: Impact of the New Automotive Policy (INOVAR-AUTO). 21st International Colloquium of GERPISA, 12th-14th of June 2013, Paris, France.

[9] LEÃO C., GOULART, L. (2013). O INOVAR AUTO e os investimentos em P\&D no setor automotivo. Disponível em http://pt.slideshare.net/Inovacao/inovar-auto. Acesso em 25/01/2014.

[10] MARX, R., MELlO, A. M. (2013). New Initiatives, Trends and Dilemmas for the Brazilian Automotive Industry: The case of Inovar Auto and its impacts on Electro Mobility in Brazil. 21st International Colloquium of GERPISA, 12th-14th of June 2013, Paris, France.

[11] ICCT - International Council on Clean Transportation, Brazil's INOVAR-AUTO incentive program (2013). Disponível em: http:// www.theicct.org. Acesso em: 24/01/2014. 
[12] Reis, S. Governo cria multas pesadas para descumprimento de eficiência energética. Disponível em: http://www.automotivebusiness.com.br/noticia/16709/governo-cria-multaspesadas-para-descumprimento-de-eficiencia-energetica. Acesso em: 24/01/2014.

[13] IEMA - Instituto de Energia e Meio Ambiente. Impacto na demanda por gasolina C, por etanol hidratado e nas emissões de $\mathrm{CO} 2$ decorrentes da melhoria da eficiência energética de veículos leves do ciclo Otto (2013). Disponível em:

http://www.energiaeambiente.org.br/documentos/Regime_Automotivo_draft.pptx\&sa=U\&ei= DMR-U47_LuexsQSg64DgCA\&ved=0CA0QFjAH\&client=internal-udscse\&usg=AFQjCNFw7erYLzRuOgbRx5bNIVKSQr-1cA. Acesso em: 05/05/2014. 